\title{
The problem of assessing the economic effect of the "smart city" concept introduction in Russia
}

\author{
Pavel Pimenov ${ }^{1, *}$, Maxim Gordeev ${ }^{2}$, Natalia Petrova $^{3}$, and Rita Fedorova ${ }^{4}$ \\ ${ }^{1}$ Saint-Petersburg State University, Universitetskaya nab., 7/9, 199034 Saint-Petersburg, Russia \\ ${ }^{2}$ ITMO University, Kronverksky Ave., 49, 197101 Saint-Petersburg, Russia \\ ${ }^{3}$ Saint-Petersburg State University of Economics, Sadovaya Str., 21, 191023 Saint-Petersburg, Russia \\ ${ }^{4}$ Saint-Petersburg State Agrarian University, Peterburgskoe shosse, 2, 196601 Saint-Petersburg, \\ Russia
}

\begin{abstract}
The issue of assessing the economic effect of the «smart city" concept introduction in modern scientific research is reduced to building ratings based on the direct effect of the model. The authors of this article suggest focusing on the calculation of both direct and indirect factors that allow evaluating more objectively the economic and social impact of investment decisions. In this paper, calculations are made on the example of the" smart city " of Moscow, where the high role of indirect factors affecting budget efficiency is determined.
\end{abstract}

\section{Introduction}

Over the past decade, the spread of digitalization and aggregation of information has given impulse to the development of the "smart city" concept.

The smart city model is an urban planning concept for integrating various information and communication technologies (ICTs), including Internet of things (IoT) systems, to manage urban infrastructure: transport, education, healthcare, housing and utilities systems, and security. This concept is being actively developed in Europe. It has not yet been widely used in Russia, but the country's largest cities (Moscow and St. Petersburg) have already accumulated experience in implementing projects [1].

The restructuring of the management system in accordance with the model of urban infrastructure adopted in the region has a social and economic effect. The economic effect is the difference between the results of an economic entity's activities and the costs incurred to obtain them. At the current stage of development, projects implementation costs are known. For example, by the end of 2019, the market volume of solutions for "smart cities" in Russia exceeded 81 billion rubles [2]. Nevertheless, the question of evaluating economic results remains open. Considering mainly state funding of smart city projects, determining their economic impact is important for evaluating budget efficiency. The scientific community focuses on solving the problem mainly through the formation of a rating integral evaluation indicator, which is a single index. This approach is used in the works of

\footnotetext{
* Corresponding author: pavpimenov@gmail.com
} 
Chinese (Sun Yu and Cui Ying "Analyzing urban infrastructure economic benefit using an integrated approach" [3]) and Brazilian (Jersone Tasso Moreira Silva, Hugo Tadeu, Rafael Pillon "Economic Development Analysis for Smart Cities: A New Approach for Management and Innovation Practices") [4] scientists, as well as in the IQ rating of cities prepared by the Ministry of construction and housing and communal services of the Russian Federation to compare the achievements of regions in Digitalization [5].

The authors of this article believe that with this approach, it is impossible to assess budget efficiency, since sufficient data is not considered. The assessment of the smart city project through the KPIs allocated during the project implementation is also biased due to the high share of indirect factors.

The authors propose to adjust the assessment of the economic effect of the smart city program by considering not only direct but also indirect factors of influence. The objectives of the work are to consider the main obstacles to the application of the standard approach to evaluating "smart cities", as well as to justify a set of factors that give an objective level of assessment. In the future, the authors will use their findings as to the basis for their own model for assessing the economic impact of the introduction of the "smart city" concept.

\section{Materials and methods}

The main barriers to an objective assessment of the economic effect are:

- high proportion of indirect factors in project implementation;

- the level of economic development of the region at the beginning of the experiment;

- environmental factors that affect economic indicators (for example, changing the location of the company's head office may lead to an unpredictable outflow of the city's profit, which will lead to a decrease in economic indicators);

- insufficient development of mechanisms for collecting more complete data to produce comprehensive statistics;

- the need to consider the innovation life cycle. Smart cities are also characterized by stages of market entry, maturity, and saturation, so the evaluation of results should consider the expected growth rate of the economic effect depending on the stage of the life cycle;

- index-based statistics do not match actual results.

The approach proposed by the authors is based on a combined consideration of both direct and indirect factors of urban infrastructure development. Moreover, given the expansion of the results from the introduction of the "smart city" model in indirect factors, the authors suggest that it is necessary to consider the spectrum of indirect factors more widely.

It is proposed to use the indicators of the integrated model of Jersone Tasso Moreira Silva, Hugo Tadeuand, Rafael Pillon «Economic Development Analysis for Smart Cities: A New Approach for Management and Innovation Practices» as the basis for forming a set of direct factors for project evaluation [4]. To assess the effectiveness of the Russian statistical accounting, the following criteria are taken:

1. Investment effect (shows improvement of the social and investment climate in the region).

2. the Share of digital services in the Gross regional product (hereinafter-GRP) and Gross value added (hereinafter referred to as GVA), since the task of the "smart city" concept, among other things, is to form innovative production.

As for indirect factors, the authors concluded that the optimal approach is to identify 1015 factors grouped into 2 main blocks:

- indirect factors determined by the main direction of financing;

- indirect factors that can be identified in specific areas of urban infrastructure and are related to digitalization, logistics changes, environmental transformation, etc. 
Thus, the relationship between direct and indirect factors has the form (Fig. 1):

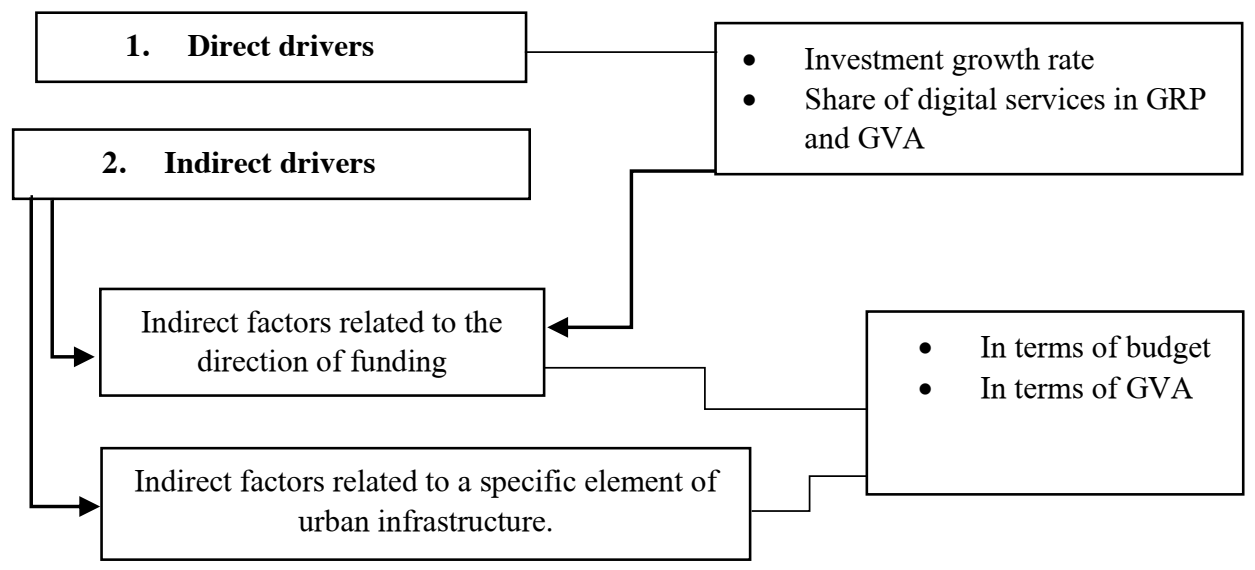

Fig. 1. Scheme for assessing the economic effect of the "smart city" model

\section{Results and discussion}

In this paper, calculations were made of direct and indirect indicators of the "smart city" model economic effect in Moscow, where the project has been introduced since 2010 [6]. This project was chosen mainly because it is the oldest in Russia with detailed statistical information.

Let us consider the direct investment effect and the indirect effect of improving transport safety in terms of the impact on GRP growth. To calculate the increase in investment, we will use official statistics [7,8]. The algorithm for calculating the direct effect used by the authors is as follows:

- the indicators selected for analysis (table 1) are presented in current prices, so they need to be adjusted for the level of inflation in the period;

- then the obtained values are smoothed out by determining the average investment value for two periods;

- the average growth rate for the 5 years preceding the introduction of the smart city model is calculated. This will allow to identify the approximate size of natural growth;

- the smoothed growth minus natural growth is determined.

The standard formula for calculating the arithmetic mean and the value cleared of inflation was used for the calculation. The calculation result is shown in Table 1 and Figure 2.

Table 1. Calculation of the investment effect of the introduction of the "smart city" concept.

\begin{tabular}{|c|c|c|c|c|c|c|}
\hline Year & $\begin{array}{c}\text { Investments } \\
\text { in fixed } \\
\text { assets, million } \\
\text { rubles }\end{array}$ & $\begin{array}{c}\text { Regional } \\
\text { inflation for } \\
\text { the period }\end{array}$ & $\begin{array}{c}\text { Investments } \\
\text { are free of } \\
\text { inflation, } \\
\text { million rubles }\end{array}$ & $\begin{array}{c}\text { Moving } \\
\text { average }\end{array}$ & $\begin{array}{c}\text { Growth } \\
\text { rate }\end{array}$ & $\begin{array}{c}\text { Growth rate, } \\
\text { purified from } \\
\text { natural growth }\end{array}$ \\
\hline 2005 & 389755,7 & $7,8 \%$ & 361554,5 & & & \\
\hline 2006 & 516329,6 & $8,1 \%$ & 477861,7 & & & \\
\hline 2007 & 634310,3 & $11,2 \%$ & 570371,6 & 567358,8 & & \\
\hline 2008 & 735508,1 & $12,5 \%$ & 653843,1 & 589002,3 & 103,8 & \\
\hline 2009 & 593434,6 & $9,3 \%$ & 542792,1 & 627945 & 106,6 & \\
\hline 2010 & 732761 & $6,6 \%$ & 687199,7 & 676198,9 & 107,7 & 2,5 \\
\hline
\end{tabular}


Table 1. Continued

\begin{tabular}{|c|c|c|c|c|c|c|}
\hline 2011 & 856424 & $7,2 \%$ & 798605 & 876822,8 & 129,7 & 24,5 \\
\hline 2012 & 1220097 & $6,6 \%$ & 1144664 & 1093134 & 124,7 & 19,5 \\
\hline 2013 & 1413094 & $5,8 \%$ & 1336133 & 1287223 & 117,8 & 12,5 \\
\hline 2014 & 1541884 & $11,7 \%$ & 1380874 & 1356105 & 105,4 & 0,1 \\
\hline 2015 & 1543601 & $14,2 \%$ & 1351310 & 1445686 & 106,6 & 1,4 \\
\hline 2016 & 1712239 & $6,7 \%$ & 1604873 & 1633942 & 113,0 & 7,8 \\
\hline 2017 & 2007708 & $3,2 \%$ & 1945642 & 1962133 & 120,1 & 14,9 \\
\hline 2018 & 2429320 & $4,0 \%$ & 2335885 & 2335885 & 115,3 & 10,1 \\
\hline
\end{tabular}

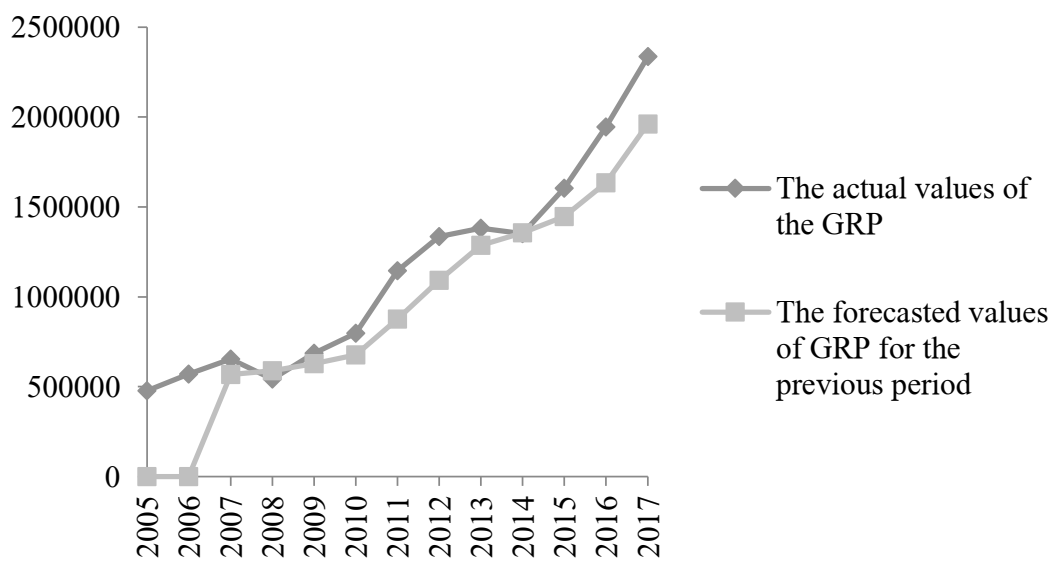

Fig. 2. Moving average of Moscow investments for the period 2005-2017, million rubles

Analysis of Table 1 data showed that after 2010, the forecast value of the moving average is lower than the actual value of the GRP. This may indicate unrecorded data that affected the outperforming growth of investments over the period. These unaccounted data can be considered as a new program for the development of a "smart city". Considering changes in the context of growth rates allows us to give an approximate picture of the "smart city" model introduction effect. In 2011, there was a significant change in the growth rate with a decline in 2014 to almost zero and an of $10.9 \%$ average rate since 2016. Of course, global long-term economic effects have an impact on the growth rate. 2011-2012 is a period of active recovery after the 2008 crisis (as known, global crises are characterized by a sharp drop and a long recovery period); 2014-2015 is the beginning of sanctions pressure and the oil crisis.

These events reduce the ability to identify objective growth due to the transformation of urban infrastructure. However, the authors, based on the expected structure of the urban infrastructure model introduction effect, similar to the schedule of the innovation life cycle, assume the maximum increase from the introduction of the model at the level of $15-17 \%$, achieved in 2015 with a gradual balancing at the level of $10 \%$ of additional growth due to the deferred effect. Over 10 years, according to the slope of the model, we can assume an increase in investment from the introduction of the model by $50-55 \%$ from the indicator of 2009.

The greatest indirect effect is observed in the transport industry. Therefore, the paper evaluated the relationship between increased transport safety and GRP growth. The authors note that because of digitalization of the transport system, there is an increase in the level of security, and, therefore, the preservation of the working-age population. The victims of road accidents are often citizens under 50 years old - the main factor of production and a 
source of economic growth. In accordance with the estimation method proposed by the Russian Center For infrastructure Economics, the corresponding indirect effect was calculated [9] (Table 2).

Table 2. Calculation of the effect of improving transport safety in terms of GRP growth

\begin{tabular}{|l|l|c|c|c|c|c|c|}
\hline \multicolumn{1}{|c|}{ Indicator/year } & $\mathbf{2 0 1 1}$ & $\mathbf{2 0 1 2}$ & $\mathbf{2 0 1 3}$ & $\mathbf{2 0 1 4}$ & $\mathbf{2 0 1 5}$ & $\mathbf{2 0 1 6}$ & SUM \\
\hline Moscow's gross regional product, mln. RUB & 9949 & 10667 & 11815 & 12780 & 13521 & 14238 & \\
\hline $\begin{array}{l}\text { Losses because of road accidents per 100 } \\
\text { thousand people. }\end{array}$ & 7,3 & 6,7 & 6,9 & 7,3 & 5,5 & 4,5 & \\
\hline $\begin{array}{l}\text { Effect of improving transport safety in } \\
\text { comparison with losses in the initial period, } \\
\text { mln. RUB }\end{array}$ & $-8,97$ & $-9,14$ & $-17,00$ & $-25,25$ & $-14,29$ & $-10,75$ & \\
\hline $\begin{array}{l}\text { GRP growth from project implementation, } \\
\text { mln. RUB }\end{array}$ & $-57,1$ & $-0,982$ & $-43,49$ & $-41,18$ & 53,51 & 16,79 & $(72,34)$ \\
\hline
\end{tabular}

The increase in GRP indicates that the losses to the economy from road accidents are lower than in the previous period. A negative value indicates an increase in the withdrawal of funds from the economy. It is easy to see that the final increase in GRP and the tax effect is negative. The value of each person's life for the economy is increasing. Because of the death of a person, budget losses increase. However, here it is necessary to pay attention to the dynamics. First, when comparing the drop in GRP at the beginning of the period and over 6 years of project implementation, it is possible to see that the drop is comparable. This means that every year the decline is reduced (the period 2013-2014) and the effect of the urban infrastructure reorganization begins to take. This correlates with the authors' assumptions about the deferred effect of indirect factors. Second, it's necessary to pay attention on trends. In 2015, there was a strong drop in the death rate, and in 2016 this trend continued. This change was also reflected in the growth of GRP (54 and 17 million, respectively).Thus, the introduction of the new urban infrastructure model allowed not only to return $0.55 \%$ of GRP that regularly fell out of economic growth, but also to generate an additional $0.24 \%$ of GRP in 2015 and 2016.

Therefore, using direct and indirect methods for assessing the economic effect of the modern urban infrastructure model's introduction allows us to identify the increase more objectively in GRP in the region. So, for 2016, the indirect effect relative to the direct one for the considered indicators is $3.07 \%$. Thus, we were convinced that the analysis of the indirect effect with a sufficient number of indicators (from 10 to 15) allows us to see a broad picture of changes that clearly indicate the level of budget efficiency and payback of "smart cities" projects.

\section{Conclusion}

- Assessment of the economic impact of the smart city project is a complex indicator that requires big data analysis. The lack of statistics today reduces the objectivity of assessing the economic effect of the program.

- Current integrated assessment indicators focus on direct economic factors, losing sight of the huge indirect effect.

- Due to the influence of the external environment and the continuing "natural" economic growth of the region, direct factors should be adjusted.

- Interpretation of the obtained indicators plays an important role in the analysis of the economic effect of implementing the smart city concept.

The conclusions obtained as a result of the analysis will be used by the authors in further scientific work. 


\section{References}

1. Smart cities, http://www.tadviser.ru/index.php/

2. A. Belitsky, Kommersant, 57, 7, https://www.kommersant.ru/

3. Y. Sun, Y. Cui, Cities, 79, 124 (2018)

4. Jersone Tasso Moreira Silva, Hugo Tadeu, Rafael Pillon, Australian Journal of Basic and Applied Sciences, 9(11), 863 (2015), https://minstroyrf.gov.ru/

5. Merging the real and virtual. How does a smart city work?, https://www.mos.ru/

6. Federal state statistics service, https://rosstat.gov.ru/

7. Department of the federal state statistics service for the city of Moscow, https://www.mosstat.ru/

8. Transport infrastructure and economic growth, https://www.infraeconomy.com/ 